\title{
PARÂMETROS BIOÉTICOS PARA A CONSIDERAÇÃO DAS FUTURAS GERAÇÕES NA DELLBERAÇÃO AMBIENTAL
}

\author{
Bioethic parameters for the consideration of future generations in \\ environmental deliberation
}

Recebido: 11.04.2018 | Aceito: 14.10.2018

\begin{abstract}
Leonardo da Rocha de Souza
Pós-doutor em Direito (UFRGS). Doutor e Mestre em Direito (UFRGS). Bacharel em Direito (UNISINOS). Licenciado em Ciências Sociais (ULBRA). Especialista em Ética e Filosofia Política (UCS). Diplomado pela Escola Superior da Magistratura (AJURIS). Professor da Universidade Regional de Blumenau (FURB) (2017-atual). Procurador do Município de Caxias do Sul-RS (2009-2017). Professor Adjunto da Universidade de Caxias do Sul.

E-mail: leorochasouza@gmail.com. Lattes: http://lattes. cnpq.br/0486274110970836
\end{abstract}

Jéssica Garcia da Silva Maciel

\begin{abstract}
Pós-graduanda em Direito Público na Escola Superior da Magistratura Federal (ESMAFE). Graduada em Direito pela Universidade de Caxias do Sul (2016). Advogada atuante na área de Direito Público. Conciliadora judicial pelo Tribunal Regional Federal da $4^{\mathrm{a}}$ Região (TRF4a e pelo Tribunal de Justiça do Rio Grade do Sul (TJRS). E-mail: jgsmaciel@ucs.br. Lattes: http://lattes.cnpq. br/6976634549519882
\end{abstract}

REsumo: O reconhecimento das futuras gerações na deliberação ambiental é necessária em virtude da complexidade das interferências feitas pelas presentes gerações. Nesse sentido, busca-se verificar de que modo ocorre a deliberação ambiental e como as futuras gerações são vistas pelos deliberantes. Utiliza-se como parâmetros para consideração das futuras gerações as propostas de Jürgen Habermas, que, na obra "O Futuro da Natureza Humana", dedicou-se a essa problemática apresentando uma ética que se preocupa com o futuro da natureza humana, que planeja proteger os nossos descendentes das consequências das atitudes atuais. Como resultado, percebe-se que os parâmetros bioéticos apontados por Habermas podem ser alargados e aplicados à consideração das futuras gerações na formação de normas e políticas públicas na área ambiental.

Palavras-chave: Futuras Gerações. Democracia deliberativa. Deliberação Ambiental. Bioética. Sustentabilidade.

Aвstract: The recognition of future generations in environmental deliberation is necessary because of the complexity of the interference made by the present generations. In this sense, it seeks to verify how environmental deliberation occurs and how are seen by the deliberators. Our proposal is used as ideas for consideration of future generations the parameters suggested by Jürgen Habermas in the book "The Future of Human Nature" in which he studies this subject presenting an ethics that is concerned with the future of human nature. This ethic plans to protect our descendants from the consequences of current attitudes. As a result, it can be seen that the bioethical parameters pointed out by Habermas can be extended and apllied to the consideration of future generations in the formation of norms and public policies in the environmental area.

Keywords: Future generations. Deliberative democracy. Environmental deliberative. Bioethics. Sustainability 
SuMÁRIO: 1 Introdução - 2 Democracia Deliberativa de Habermas e Proteção Ambiental - 3 A Consideração das Futuras Gerações na Deliberação Ambiental - 4 Parâmetros Bioéticos para Proteção das Futuras Gerações - 5 Conclusão.

\section{INTRODUÇÃo}

A preservação do meio ambiente é um direito constitucional ${ }^{1}$ destinado às presentes e futuras gerações. Porém, também é um dever imposto à comunidade e ao Poder Público, representado pelos três poderes. Ao Poder Legislativo atribui-se a responsabilidade de edição e aprovação de normas que regulam a sociedade. Ao Poder Executivo atribui-se a responsabilidade de aplicação dessas normas por meio de políticas públicas e do poder de polícia, podendo responder por suas ações e omissões. Ao Poder Judiciário atribui-se a responsabilidade de interpretação e aplicação das normas que regem o Direito.

$\mathrm{O}$ advento de novas tecnologias e de novos processos de produção gerou profundas mudanças nas relações econômicas e sociais no século XX, o que refletiu na alteração da legitimidade e da organização do poder, levando as instituições a novas formas de atuação. Uma das mudanças diz respeito à atuação do Estado nas ameaças provenientes da sociedade do risco: se antes era possível atuar para combater ou remediar as consequências de desastres ecológicos, por exemplo, agora é necessário prevenir. ${ }^{2}$

Habermas traz duas possibilidades de atuação humana no progresso das ciências biológicas e no desenvolvimento das biotecnologias: ou agimos de forma autônoma, "segundo considerações normativas que se inserem na formação democrática da vontade", ou agimos de forma arbitrária, de acordo com nossas preferências subjetivas "que serão satisfeitas pelo mercado". A escolha entre uma e outra forma definirá se temos a autocompreensão da responsabilidade de nossas ações e de que forma isso ocorre. ${ }^{3}$ Por isso, a necessidade de pensar em parâmetros bioéticos para a consideração das futuras gerações na deliberação ambiental.

Antonio Hermann Benjamin ${ }^{4}$ alerta que as "atividades humanas estão, permanentemente, pondo em perigo a biodiversidade planetária", podendo-se vislumbrar as pesquisas e modificações biotecnológicas dentre essas atividades humanas. Isso porque as biotecnologias podem gerar alterações nos ecossistemas, considerados "um reservatório extraordinário e ainda inexplorado de informações bioquímicas e genéticas, capazes, quem sabe, de modificar, para melhor e por inteiro, nosso futuro, permitindo-nos saltos tecnológicos atualmente nem sequer imaginados." ${ }^{5}$

A necessidade de garantir às futuras gerações o acesso equitativo ao meio ambiente exige a aplicação de princípios como in dubio pro natura e da equidade intergeracional. Porém, esses princípios podem ser aplicados sem a devida precisão ocasionando a existência de riscos irreversíveis provenientes de equívocos na sua interpretação e aplicação. Com o intuito de bem conservar o sistema ecológico mundial, vital para a preservação das gerações atuais e futuras, e tendo em vista que muitos dos recursos disponíveis na natureza são finitos, é necessário, ainda, observar-se a imprescritibilidade da reparação de danos ambientais. 
Além desses parâmetros aplicáveis à consideração das futuras gerações, propõe-se buscar outros indicadores, especificamente na obra "O Futuro da Natureza Humana" de Jürgen Habermas. Nesse livro, Habermas aponta parâmetros bioéticos para pesquisas e aplicações de técnicas genéticas, discutindo situações que envolvem modificações genéticas para fins terapêuticos. A proposta deste artigo é buscar a essência dos limites bioéticos apontados por Habermas e ampliá-los para uma orientação geral da consideração das futuras gerações na deliberação ambiental.

Para isso, adota-se o método indutivo, partindo do estudo de parâmetros bioéticos em casos de eugenia, e aplicando-os ao direito das futuras gerações em sentido lato. Realiza-se uma pesquisa bibliográfica a partir de referenciais teóricos que indicam parâmetros éticos de prevenção da identidade das gerações vindouras, começando-se por um estudo da democracia deliberativa a partir dos ensinamentos de Jürgen Habermas (2), passando-se, após, ao estudo das futuras gerações e das necessidades de sua proteção (3). A seguir, estudam-se os parâmetros éticos apontados por Habermas para atendimento dos interesses das futuras gerações (4).

\section{Democracia deliberativa de habermas e ProteÇÃo ambiental}

Para que haja a formação legítima do Direito há que se observar o modo como ocorrem as deliberações. Uma democracia deliberativa efetiva-se no momento em que os interesses sociais são postos em um processo de comunicação entre os sujeitos afetados pela norma. Jürgen Habermas define, no princípio do discurso, que "são válidas as normas de ação às quais todos os possíveis atingidos poderiam dar o seu assentimento, na qualidade de participantes de discursos racionais". 6

Na tentativa de aplicar a democracia deliberativa aos bens ambientais, constata-se que as futuras gerações (dentre outros atores sociais) carecem de voz para deliberar. Surge, a partir dessa análise, a seguinte questão: de que maneira os direitos das gerações futuras estão sendo garantidos nas deliberações ambientais?

O direito surge como instrumento estabilizador dessa problemática e, para isso, se utiliza da força social da ação comunicativa. O Estado produz um equilíbrio quando o instrumento do Direito é utilizado para organizar comunidades jurídicas que se afirmam em dado ambiente social. Supõe-se, assim, que os acordos firmados sejam elaborados sob forma universalizável utilizando-se o princípio do discurso para serem aceitos como válidos. ${ }^{7}$

Assim, mais efetivo será o Direito se houver uma discussão democrática em relação ao seu conteúdo, pois os afetados pela norma estão aptos a entender o motivo de sua elaboração e a necessidade de seu cumprimento. Isso permite que "os destinatários da norma" sejam "também seus autores". "O direito passa a ser visto como um instrumento estimulador da ação comunicativa, que não depende de garantias metassociais para que ocorra a estabilidade social, mas da compreensão dos atores sociais". ${ }^{8}$

A democracia concreta permite que os cidadãos atingidos pela norma possam exercer, através de sua participação nas deliberações, o que Habermas chama de "poder ser si mesmo" ${ }^{\prime \prime}$, que é garantido quando se tem liberdade de escolher o próprio destino sem a imposição de determinada influência. 
Há diversos motivos para que alguém respeite a lei. Porém, Habermas acredita que a lei deve ser obedecida por sua validade e aceitabilidade racional. José Pedro Luchi propõe que "quanto menos legitimada uma norma ou um conjunto de normas, mais sua observância dependerá de intimidação, poder das circunstâncias, costume ou mero hábito." 10 A validade e aceitabilidade racional da norma, desejados por Habermas, consumam-se no momento em que a comunicação, em espaços públicos, possua liberdade de temas e contribuições para que se chegue a um acordo:

O direito moderno tira dos indivíduos o fardo nas normas morais e as transfere para as leis que garantem a compatibilidade das liberdades de ação. Estas obtêm sua legitimidade através de um processo legislativo que, por sua vez, se apóia no princípio da soberania do povo. [...] O processo legislativo democrático precisa confrontar seus participantes com as expectativas normativas das orientações do bem da comunidade, porque ele próprio tem que extrair sua força legitimadora do processo de um entendimento dos cidadãos sobre regras de sua convivência. ${ }^{11}$

A validade da norma provém da vontade dos próprios cidadãos, e sua elaboração costuma ficar a cargo do legislador político. Porém, surge a indagação: como as normas impostas através da maioria serão aceitas pela minoria? Habermas, em sua teoria do discurso reconhece que o devido processo democrático, que garanta a deliberação nas decisões, deve observar tanto a política liberal (na qual o processo se realiza exclusivamente por meio de direitos fundamentais liberais), quanto a política republicana (que sugere a formação da vontade como um autoentendimento ético-político). "Em contrapartida a política deliberativa depende da institucionalização dos processos comunicacionais da política deliberativa e do jogo entre deliberações institucionalizadas e opiniões públicas que se formaram de modo informal."12

Ou seja, para que se obtenha resultados racionais, é necessário que haja procedimentos discursivos nas negociações ambientais e somente assim o direito será a melhor tradução dessas deliberações aos cidadãos. A deliberação ambiental é um tema importante para a sociedade e possui carência de regulamentação em razão da constante mudança da realidade ambiental, que pode se transformar em decisões judiciais, legislativas ou em políticas públicas. Os participantes de um processo deliberativo, ao exprimirem opiniões racionais no tocante aos problemas ambientais, controlam o exercício do poder político na preservação de recursos naturais ou no combate a atitudes poluidoras, cabendo ao Estado agir, influenciado por opiniões públicas formadas por discursos racionais. ${ }^{13}$

Em uma democracia deliberativa convoca-se a comunidade a participar da elaboração de leis. No entanto, cada indivíduo possui objetivos e visões diferentes na deliberação: enquanto alguns, por exemplo, defendem a preservação, outros defendam o desenvolvimento. Há que se chegar a um acordo por meio da discussão e da exposição de argumentos, para que assim haja uma melhor aceitação e efetividade da nova lei. As teorias da razão comunicativa e da democracia deliberativa, criadas por Habermas, surgem como parâmetros éticos à deliberação ambiental, no sentido de consolidar a participação igualitária de todos os atingidos pela norma ambiental por meio do agir comunicativo. 


\title{
3. A CONSIDERAÇÃo DAS FUTURAS GERAÇÕES NA DELIbERAÇÃO AMBIENTAL
}

Hans Jonas em sua obra "O Princípio Responsabilidade" nos traz o princípio ético da responsabilidade, que leva em conta os impactos a longo prazo das atitudes humanas e sua irreversibilidade. No dizer de Jonas:

\begin{abstract}
Um imperativo adequado ao novo tipo de agir humano e voltado para o novo tipo de sujeito atuante deveria ser mais ou menos assim: "Aja de modo a que os efeitos da tua ação sejam compatíveis com a permanência de uma autêntica vida humana sobre a Terra"; ou, expresso negativamente: "Aja de modo a que os efeitos da tua ação não sejam destrutivos para a possibilidade futura de uma tal vida"; ou, simplesmente: "Não ponha em perigo as condições necessárias para a conservação indefinida da humanidade sobre a Terra"; ou, em um uso novamente positivo: “'Inclua na tua escolha presente a futura integridade do homem como um dos objetos do teu querer." 14
\end{abstract}

Segundo a proposta de Hans Jonas, a ética da responsabilidade é cumprida quando se deixa ao futuro um meio ambiente em condições iguais de fruição ao que dispomos hoje, ou seja, o dever é não interferir na continuação do meio ambiente para as futuras gerações. Habermas, em sua obra "O Futuro da Natureza Humana", preocupa-se com os interesses das futuras gerações e de que forma será regulada a responsabilidade quanto às intervenções humanas, se normativamente regulada ou sem autodelimitações (de acordo com preferências individuais). ${ }^{15}$

A primeira alternativa tende a ser a solução, eis que, comumente, os interesses dos presentes à deliberação ambiental prevalecem sobre os interesses daqueles que ainda não existem. A norma traria limite à deliberação, impedindo que se ultrapassasse os interesses das futuras gerações.

De qualquer forma, corre-se o risco de reduzir a liberdade de atuação das futuras gerações em cada decisão ambiental tomada. Caso não haja responsabilidade solidária que garanta o "poder ser si mesmo", as ameaças ao meio ambiente tornam-se hábitos que geram indiferença aos direitos do outro. É necessário reconhecer a vulnerabilidade das futuras gerações, já que não podem defender seus próprios interesses. ${ }^{16}$

A compreensão normativa do "poder ser si mesmo" garante às futuras gerações uma vida sem imposições passadas. Essa compreensão normativa é ameaçada pelo aumento de intervenções técnicas sobre a natureza, devido ao desenvolvimento econômico atrelado à liberdade de escolhas privadas do indivíduo. Porém, a soma desses fatores levam a intervenções decisivas em relação ao meio ambiente, que podem não estar voltadas a interesses coletivos e, sim, a interesses individuais e econômicos. A geração atual, ao deliberar em matéria ambiental, está limitada a seus valores pessoais. Com isso, essa deliberação corre o risco de não considerar os interesses das futuras gerações, eis que as gerações presentes pode não compartilhar dos mesmos valores e da mesma história de vida das gerações futuras. $^{17}$

O princípio fundamental da dignidade da pessoa humana ${ }^{18}$ previsto no artigo $1^{\mathrm{o}}$, III, da Constituição Federal, deve ser compreendido como um paralelo entre os direitos das presentes e das futuras gerações, vez que há de ser sustentado todo o patrimônio ambiental e cultural em prol das garantias fundamentais do ser humano. 
Mesmo que o direito das gerações futuras esteja assegurado por normas nacionais e internacionais, o desenvolvimento para evolução da atual sociedade acarreta desequilíbrio ambiental. Ao passo que a ciência e as tecnologias tomam lugar no mundo para melhorar as condições de vida dos indivíduos, esses sentem seus direitos individuais ameaçados, pois, para criação de inovações tecnológicas, muitas vezes, é preciso de recursos naturais esgotáveis. Além disso, a biotecnologia utiliza organismos vivos para a produção de bens e serviços e aumenta o consumismo, ou seja, a natureza está sendo manipulada com o propósito de captar lucro, ameaçando mais uma vez a humanidade. ${ }^{19}$

Asnormasjurídicas exercem opoder sobreoâmbito político, financeiro, socioambiental e ecológico, mas, apesar de notáveis os esforços do legislador, o cumprimento de tais normas nem sempre se realiza. O futuro ecológico é guiado pelo sistema econômico. Logo, o sistema jurídico sozinho não basta para solucionar as controvérsias acerca da situação do ecossistema ${ }^{20}$, ainda mais levando em conta que a insuficiência de recursos humanos e os erros processuais acarretam na diminuição da eficácia nos processos relacionados a danos ambientais.

É necessário descobrir um meio para a aplicação do princípio da equidade intergeracional, o qual, através de solidariedade e inclusão, busca a preservação para as presentes e futuras gerações. O ser humano vive reciprocamente com a natureza e nada menos do que recebeu das gerações passadas deve ser deixado as próximas gerações.

Sobre esse assunto, ensinam Sarlet e Fensterseifer:

[...] pode-se dizer que, no compasso da evolução histórica dos direitos fundamentais, passou-se da perspectiva do indivíduo à da espécie humana, considerada inclusive em perspectiva futura, através da proteção jurídica dos interesses das futuras gerações. Assim como, das liberdades individuais migrou-se à solidariedade planetária. ${ }^{21}$

Demonstra-se indiscutível a responsabilidade que a geração existente possui com a geração subsequente. Como a previsão normativa nem sempre pressupõe a proteção das futuras gerações, paradigmas éticos devem ser observados para conduzir a comunidade a um comprometimento com os que carecem de voz, dado que a natureza humana e não humana deve encontrar no próprio ser humano o seu maior protetor. Esses paradigmas são buscados nos parâmetros bioéticos apontados por Habermas, conforme estuda-se a seguir.

\section{Parâmetros bioéticos para proteção das futuras gerações}

Habermas, no seu princípio do discurso, defende que somente são válidas as normas às quais todas as pessoas afetadas possam participar por meio de um discurso racional. Os destinatários da norma só podem ganhar autonomia à medida que possam compreender-se como autores das leis às quais eles mesmos estão submetidos ${ }^{22}$.

Portanto, a democracia deliberativa defende que a legitimidade do Direito deve estar sustentada pela deliberação dos indivíduos em espaços de debate e negociação. Há uma preocupação em estender a participação dos cidadãos de interesses similares no processo de 
deliberação, como forma de assegurar plena legitimidade às decisões. A dificuldade ocorre, na área ambiental, quando a participação das presentes gerações em uma deliberação ameaça a expectativa de direitos de futuras. Desse modo, aflora a necessidade de examinar qual a relação de responsabilidade estabelecida do presente para com o futuro. Para essa questão é preciso transcender o limite temporal, para promover uma solidariedade intergeracional que considere os interesses e os direitos das gerações atuais e futuras.

Nesse sentido, um novo contrato social intergeracional é proposto por Henrique Lian:

Um contrato intergeracional, no entanto, só pode se dar no plano hipotético. Sendo assim, seriam necessários mecanismos reguladores pelos quais, mesmo vivendo (e contratando) em momentos distintos do tempo, os cidadãos do futuro o ratificariam em todas as suas cláusulas hipotéticas, tal a universalidade e atemporalidade de seus princípios, tal a força equitativa de seus acordos e tal o cuidado com a preservação de toda expectativa de direito futuro. ${ }^{23}$

Frente ao atual contexto de ameaças a diversas formas de vida, combinado com a incerteza científica, considerar as futuras gerações pode estar relacionado à própria sobrevivência das espécies, atuais e futuras. A sociedade de risco, na qual há ameaças de diversas espécies, também é resultado do momento de inovação tecnológica. Por isso, é necessário que haja limites para a intervenção humana incerta e perigosa.

José Esteve Pardo propõe uma teoria da decisão judicial na incerteza e reflete que o problema da incerteza científica para o direito parece ter dois objetivos centrais. O primeiro objetivo seria estabelecer em seus termos essa problemática:

O que acontece é que o direito não deve basear suas decisões - não foi essa sua tendência ao longo da história - em certezas científicas ou na experiência. São outros elementos e valores que tem sido tomados prioritariamente em consideração ao decidir. Neste sentido, a incerteza que o conhecimento científico reconhece tantas vezes certamente não favorece a adoção das inevitáveis decisões pelas correspondentes instâncias jurídicas e pelos poderes públicos. ${ }^{24}$

Essa incerteza que domina a ciência não pode dominar o direito eis que cabe ao direito o poder de decisão. $\mathrm{O}$ direito deve estar a par de suas atribuições e em consonância com seus instrumentos a fim de responder ao desafio de manter sua finalidade decisória nesses meios de incerteza.

O segundo objetivo para construir uma teoria da decisão na incerteza, conforme Pardo, é a determinação de três elementos: “a) elemento subjetivo: quem decide ou pode participar na tomada de decisões?; b) elemento procedimental: qual procedimento deve moldar essas decisões?; c) critérios materiais de decisão: quais bens, valores ou referências são levados em consideração quando se trata de cenários de incerteza?". ${ }^{25}$ 
E também há que abordar um componente muito importante na determinação do marco da decisão. Um tema delicado e complexo que se vislumbra no final desses tortuosos caminhos decisórios e, inclusive, além deles, como um disparo retardado: a questão da responsabilidade pelas decisões em condições de incerteza, responsabilidade por danos que possam ter ocorrido como resultado de algumas decisões tomadas, por assim dizer, às cegas. Trata-se de estabelecer um regime de responsabilidade que, segundo se delimite, incidirá também no modo de adotar decisões e que será, em princípio, menos comprometido e assumirá menos riscos se houver um regime de responsabilidade rigoroso. Se, pelo contrário, estivermos em um sistema de responsabilidade benevolente frente aos danos que possam surgir a partir de decisões na incerteza, então as instâncias decisórias não se verão tão obrigadas a ponderar o alcance de seus atos nem a sentir-se responsáveis pelos mesmos. ${ }^{26}$

A relevância dessas decisões se demonstra quando essas inovações tecnológicas não encontram limites temporais ou territoriais, não se submetem a regras de responsabilidade ou não permitem a compensação, haja vista a potencial irreversibilidade de seus efeitos. Não há como submeter a controle suposições científicas especulativas cujas características são a incerteza e irreversibilidade de suas consequências. A sociedade está exposta ao efeito de decisões que, não podendo ser garantidas, tornam o mundo um espaço físico de experimentos. $^{27}$

O Estado de direito, como forma de organização jurídica do poder político, tende a suportar diretamente os efeitos dos problemas supramencionados. Pois as inéditas tarefas impostas pela complexidade social, tais como as novas exigências de democracia de conteúdo participativo, plural e de interferência decisória, já dão indícios de que o Estado de direitos se revela incompatível e dessincronizado. ${ }^{28}$

Os problemas ambientais da geração atual requerem referências jurídicas e normativas mais apropriadas, para que sejam empregadas como parâmetro para resolução de conflitos acerca das inovações tecnológicas. Há uma nova perspectiva de ação do Estado no tocante ao planejamento do futuro através dos progressos da ciência que com as modernas tecnicidades (principalmente as genéticas e com emprego de substâncias químicas) provoca a oportunidade de autodestruição das espécies. ${ }^{29}$

Conforme aclara Canotilho, os compromissos estatais de enfrentamento de efeitos combinados das várias fontes poluentes e suas implicações globais e duradouras, ao mesmo tempo em que

[...] colocam em causa comportamentos ecológicos e ambientalmente relevantes das gerações atuais, que, a continuarem sem adopção de medidas restritivas, acabarão por comprometer, de forma insustentável e irreversível, os interesses das gerações futuras na manutenção e defesa da integridade dos componentes ambientais naturais. ${ }^{30}$

Habermas, em sua obra "O Futuro da Natureza Humana", aborda parâmetros bioéticos para o futuro da geração humana que, embora trate sobre questões de eugenia, trabalha com a ética da espécie humana e inicia com o dilema sobre o que fazer com o tempo de uma vida. A proposta, a partir deste momento do presente artigo, é trabalhar esses parâmetros como diretrizes para considerações das futuras gerações na deliberação 
ambiental.

Atualmente a filosofia não dispõe de respostas definitivas "sobre o que fazer com o tempo de uma vida", mas a filosofia junto com a história sagrada já forneceram elementos para elucidar essa incógnita. As doutrinas da metafísica eram aplicadas por todos, porém, esse modelo ético de vida diminuiu com a aceleração da transformação social. Ainda hoje, a filosofia se esforça para explicar a moral que adotamos para julgar normas e ações sempre que é necessários tratar sobre os interesses comuns. Assim, a moral e a ética colocam a preocupação com o próprio bem-estar a serviço do interesse pela justiça. Habermas esclarece que "Kierkegaard foi o primeiro a responder à questão ética e fundamental sobre os êxitos e fracassos da própria vida com um conceito pós-metafísico do poder ser si mesmo". Depreende que uma conduta ética de vida "exige do indivíduo que ele se concentre em si próprio e se liberte da dependência em relação a um ambiente dominador", ou seja, "o indivíduo precisa recobrar a consciência de sua individualidade e de sua liberdade" ${ }^{\prime 31}$.

Demaneira autocrítica, oindivíduo apropria-se de seu passado histórico, efetivamente encontrado e concretamente rememorado, tendo em vista as possibilidades de ações futuras. Somente assim ele faz de si uma pessoa insubstituível e um indivíduo inconfundível. ${ }^{32}$

Quando a demanda sobre uma ética da espécie entra em pauta, Habermas orienta que "o progresso das ciências biológicas e o desenvolvimento das biotecnologias [...] possibilitam um novo tipo de intervenção". O autor demonstra não se tratar de "uma atitude de crítica cultural aos avanços louváveis do conhecimento científico, mas apenas de saber se a implementação dessas conquistas afeta a nossa autocompreensão como seres que agem de forma responsável e, em caso afirmativo, de que modo isso se dá". ${ }^{33}$

No tocante à responsabilidade de uma pessoa ao deliberar sobre a formação própria de outra, em dissonância à responsabilidade de costume, aquela torna-se responsável pelas consequências advindas de suas decisões ao limite de sua participação, fato que intriga, na contemporaneidade, os gêneros de relações legalmente existentes. Conforme Habermas, "[...] intervenções biotécnicas evocam, não apenas difíceis questões morais, mas também propõem questões de outra espécie" ${ }^{34}$, ou seja, as intervenções repercutem tanto no mundo físico que vivemos, quanto no mundo intrínseco-reflexivo da pessoa que sofreu transformação em seu processo de constituição.

Nesse seguimento, Habermas expõe o método DGPI (diagnóstico genético de préimplantação), que resultou da combinação da "medicina reprodutiva e da técnica genética", e possibilita "submeter o embrião que se encontra num estágio de oito células a um exame genético de precaução". A intenção primeira desse método é permitir que os pais evitem a transmissão de doenças hereditárias aos seus filhos. "Caso se confirme alguma doença, o embrião analisado na proveta não é reimplantado na mãe; desse modo, ela é poupada de uma interrupção da gravidez, que, do contrário, seria efetuada após o diagnóstico prénatal." 35

Como técnicas como essa são recentes, ainda precisam de "processos políticos de autocompreensão" para que sejam utilizadas em prol do desenvolvimento global, evitando-se que se tome o estado atual da técnica como base para sua regulamentação. 
Um tratamento possível dessa matéria seria inciar considerando-a sob o enfoque de uma eugenia liberal, tanto na sociedade, como na esfera pública política ${ }^{36}$ e no parlamento. Como isso, a utilização do DGPI poderia ser considerada "por si só como moralmente admissível ou juridicamente aceitável, se sua aplicação [fosse] limitada a poucos e bem definidos casos de doenças hereditárias graves que não poderiam ser suportadas pela própria pessoa potencialmente em questão". Em uma realidade posterior, se os avanços biotécnicos e os êxitos da terapia genética assim o permitissem, poderia ser estendia sua utilização "para intervenções genéticas em células somáticas (ou até em linhagens germinativas), a fim de prevenir essas doenças hereditárias e outras semelhantes" ${ }^{37}$

Com a extensão da permissão para intervenção, Habermas defende a necessidade de separar a a eugenia negativa (que seria justificável) da eugenia positiva ("inicialmente considerada injustificada"). O paradoxo se insere no tocante à linha tênue entre as duas classes de eugenia, tendo em vista que "os limites são pouco definidos e que precisamos traçar e impor fronteiras precisas". O argumento da imprecisão de limites "já serve para defender uma eugenia liberal, que não reconhece um limite entre intervenções terapêuticas e de aperfeiçoamento, mas deixa às preferências individuais dos integrantes do mercado a escolha dos objetivos relativos a intervenções que alteram características" ${ }^{\prime 38}$.

Alerte-se, porém, que os interesses dos filhos não podem ser negligenciados diante dessas preferências individuais: os pais não podem decidir "sem supor um consenso e somente em função de suas próprias preferências". Em termos de paridade na deliberação, os pais devem considerar seus filhos como se estivessem presentes no momento da decisão, "com a intenção de entender-se com ele ao invés de tratá-lo como objeto [...] e de instrumentalizá-lo para seus próprios objetivos". ${ }^{39}$

Na mesma linha, quanto aos limites, adverte o Presidente da República da Alemanha: "Quem começa a fazer da vida humana um instrumento e a distinguir entre o que é digno ou não de viver perde o freio." ${ }^{40}$ A aceitabilidade do DGPI vincula-se à seguinte questão: "É compatível com a dignidade humana ser gerado mediante ressalva e, somente após um exame genético, ser considerado digno de uma existência e de um desenvolvimento?" Isto é, "podemos dispor livremente da vida humana para fins de seleção?" ${ }^{41}$ Ao se tentar responder a essas questões, deve-se ter em mente que a permissão para intervenções genéticas fomenta a explorabilidade econômica e, com isso, pode ser que o Estado não limite corretamente a intervenção, dada a incerteza nesse campo da ciência diante de seu rápido desenvolvimento.

O limite de uma deliberação eugênica ainda está passível de demarcação. Mas crescente evolução da biotécnica pode significar a necessidade que esses limites sejam logo estabelecidos. Enquanto isso não ocorre, essa matéria estará sujeita a pessoas que desejam ser "protagonistas da evolução" ou que desejam "brincar de Deus" enquanto promovem uma "autotransformação da espécie" 42 .

Essa situação socialmente problemática enseja uma solução pelo Poder Público uma vez que interfere diretamente na vida de todos os cidadãos. Essa solução passa pela necessidade de novas regras que se adaptem às transformações sociais. Paradoxalmente, é a autonomia da pesquisa que permite seu desenvolvimento. O Estado constitucional liberal tem por essência proteger a autonomia da pesquisa, ainda mais quando ligada à disposição técnica sobre a natureza, visto que esse gênero de pesquisa promete unir o progresso econômico e a ampliação dos limites de decisões individuais, ou seja, promete efetivar o princípio liberal que incentiva a ideia de que "todos os cidadãos devem ter a mesma chance 
de moldar sua própria vida de maneira autônoma"43.

A partir dessa compreensão, é possível que "as intervenções legislativas" reduzam a "liberdade da pesquisa biológica" e afetem o "desenvolvimento da técnica genética", opondo-se "à tendência de liberdade que domina a modernidade social". E a sociedade tende a aceitar os avanços na técnica genética se a medicina puder fundamentá-los "com a expectativa de uma vida mais saudável e mais longa". Com isso, Habermas constata que eventuais intervenções legislativas retirariam a autonomia das pessoas, mitigando o "princípio liberal de que todos os cidadãos devem ter a mesma chance de moldar sua própria vida de maneira autônoma." 44

O excesso de manipulações genéticas pode afetar a autocompreensão de cada pessoa como membro da espécie humana, a ponto de se buscar, no futuro, uma série de restrições "por meio de dispositivos legais" que garantissem "o direito fundamental a um patrimônio hereditário não-manipulado, se a ponderação moral e a formação democrática da vontade conduzissem a esse resultado". Por isso, Habermas traz dois questionamentos essenciais: (1) "queremos mesmo caminhar na direção de uma eugenia liberal, que ultrapassa objetivos rigorosamente terapêuticos?" e (2) "Quais são os princípios morais mais básicos que poderiam guiar a política pública e a escolha individual em relação ao uso de intervenções genéticas numa sociedade justa e humana, em que os poderes da intervenção genética serão muito mais desenvolvidos do que hoje?" 45.

Torna-se claro, a partir do exposto, que as intervenções eugênicas propiciarão debates e julgamentos quanto à tomada de decisões. A posição de cada um vai depender da autocompreensão, de como da pessoa age e se preocupa com a própria existência. Além disso, "também depende da maneira como nos entendemos antropologicamente enquanto seres da espécie o fato de nos enxergarmos como autores responsáveis por nossa própria história de vida e de podermos nos considerar reciprocamente como pessoas nascidas sob as mesmas condições" ${ }^{\prime 46}$. Habermas propõe o seguinte debate:

Podemos conceber a autotransformação genética da espécie como o caminho para o aumento da autonomia do indivíduo - ou com isso estaremos minando a autocompreensão normativa de pessoas que conduzem suas próprias vidas e consagram o mesmo respeito umas às outras? Caso a segunda alternativa esteja correta, não obtemos diretamente um argumento moral decisivo, mas sim uma orientação mediada pela ética da espécie e que recomenda cautela e moderação. ${ }^{47}$

As questões fundamentais observadas até o momento devem chegar a um acordo político, mas para que isso ocorra deve-se perpassar sobre um debate quanto aos argumentos morais relativos ao aborto, levando-se em conta as exigências constitucionais quanto ao pluralismo ideológico da sociedade. Habermas esclarece que o argumento utilizado é que "o embrião desfruta desde o início da dignidade humana e da absoluta proteção à vida"48.

A admissibilidade do uso de embriões para pesquisas e para o DGPI costuma ter como fundamento o mesmo debate filosófico que se realiza em torno do aborto. Para contextualizar o debate atual sobre o aborto, Habermas explica que formaram-se dois grupos: o grupo "Pró Vida" e o grupo “Pró Escolha" e, nesse enquadramento, os conservadores lutam para impedir o desenvolvimento de técnicas genéticas. No entanto, parece haver uma diferença 
entre essas matérias. A função do DGPI seria "prevenir um eventual aborto por meio da 'rejeição' de células-tronco extracorporais e geneticamente defeituosas". Assim, nesse caso, os pais desejam ter o filho, desde que o embrião atenda a padrões por eles pré-estabelecidos. Por outro lado, quando se fala em aborto, o foco está no direito da mãe de interromper uma gravidez que ela não deseja, ela vai escolher se deseja ter o filho. ${ }^{49}$

O que as duas matérias têm em comum é que o filho não está presente para fazer sua escolha. Diante dessa controvérsia, "fracassa toda tentativa de alcançar uma descrição ideologicameente neutra do status moral da vida humana prematura", pois ambas posições deixam de lado o "status moral da vida humana prematura". Um grupo define o embrião como "amontoado de células" e defende que somente ao recém-nascido "compete a dignidade humana no sentido estritamente moral". A oposição, considera todo "exemplar biologicamente determinável da espécie como um portador de direitos fundamentais". Já Habermas, arrazoa que "ambos os lados parecem não se dar conta de que algo pode ser considerado como indisponível, ainda que não receba o status de um sujeito de direitos, que, nos termos da constituição, é portador de direitos fundamentais" e, conclui que, em uma discussão quanto às normas de uma "esfera pública democrática importam apenas as proposições morais em sentido estrito", ou seja, a vida humana goza de proteção legal, independente de seus deveres e direitos. ${ }^{50}$

Nesse ponto, a problemática moral quanto a instrumentalização da vida humana ganha destaque sob o enfoque das sociedades pluralistas dado que cada comunidade possui seu próprio código moral e, nesse contexto, não autorizam que seus argumentos sejam minimizados ou subtraídos, pois sua autocompreensão se apoia em suas tradições e estilos de vida. Porém, não se pode esquecer que "a moral abstrata da razão, pertencente aos sujeitos de direitos humanos, apoia-se, por sua vez, numa anterior autocompreensão ética da espécie, compartilhada por todas as pessoas morais". Assim, Habermas questiona se tal "tecnicização da natureza humana altera a autocompreensão ética da espécie de tal modo que não possamos mais nos compreender como seres vivos eticamente livres e moralmente iguais, orientados por normas e fundamentos" ${ }^{\prime 51}$.

Habermas ensina que são irritações desse gênero que alteram o pano de fundo, a essência de dada comunidade, no caso a comunidade humana. Alerta que são nesses casos que os fatos transcendem dos filmes de ficção e adentram o comum na vida real. Profissionais das tecno-ciênciass confrontam o comum com seus discursos sobre mudanças artificiais no ser humano, como por exemplo, "o aperfeiçoamento do homem por meio de implantes de chip ou com a substituição do homem por robôs mais inteligentes" 52 .

Buchanan menciona o cenário fantasmagórico de um "comunitarismo genético", no qual diferentes subculturas levam adiante a auto-otimização eugênica da espécie humana em diferentes direções, de modo que a unidade da natureza humana enquanto base de referência, na qual, até agora, todos os homens se compreenderam como membros da mesma comunidade moral e puderam se reconhecer reciprocamente, é questionada: "Não podemos mais presumir que haverá um único sucessor para aquilo que foi concebido como natureza humana. Precisamos considerar a possibilidade de que, num certo momento do futuro, diferentes grupos de seres humanos poderão seguir caminhos divergentes de desenvolvimento usando a tecnologia genética. Se isso ocorrer, haverá diferentes grupos de seres, cada qual com sua própria natureza, relacionados uns com os outros somente por meio de um ancestral comum (a raça humana), exatamente como hoje existem diferentes espécies de animais, que evoluíram a partir de ancestrais comuns por 
meio de mutaçã aleatória e pela seleção natural".$^{53}$

Nas sociedades liberais, o mercado deixaria as decisões eugênicas à escolha dos pais. Para não haver intervenção normativa negativa aos propósitos liberais, os defensores da eugenia liberal comparam a eugenia com a educação e afirmam que a modificação genética do patrimônio hereditário é similar à modificação de atitudes por meio da socialização. "Se já se deixa a critério dos pais o modo de criar os filhos, por que então a intervenção genética para salientar os traços normais da prole deveria ser menos legítima?" Contudo, Habermas elucida que "a liberdade eugênica dos pais tem a ressalva de não poder colidir com a liberdade ética dos filhos" e este paradoxo nivela a "diferença entre o que cresceu naturalmente e o que foi fabricado, entre o subjetivo e o objetivo" ${ }^{54}$

Ao modificar a genética do filho, os pais formulam interesses que não concedem ao destinatário uma reconsideração. Esses interesses são, portanto, unilaterais e irrecorríveis. Por isso é necessário diferenciar interferência eugênica de aperfeiçoamento, eis que, em última análise supõe-se o consentimento do paciente em casos de modificação para fins terapêuticos, ou seja, no futuro a pessoa aceitaria o tratamento. ${ }^{55}$

Aplicar-se-ia, desse modo, o imperativo categórico kantiano reformulado por Hans Jonas:

Um imperativo adequado ao novo tipo de agir humano e voltado para o novo tipo de sujeito atuante deveria ser mais ou menos assim: "Aja de modo a que os efeitos da tua ação sejam compatíveis com a permanência de uma autêntica vida humana sobre a Terra"; ou, expresso negativamente: "Aja de modo a que os efeitos da tua ação não sejam destrutivos para a possibilidade futura de uma tal vida"; ou, simplesmente: "Não ponha em perigo as condições necessárias para a conservação indefinida da humanidade sobre a Terra"; ou, em um uso novamente positivo: "Inclua na tua escolha presente a futura integridade do homem como um dos objetos do teu querer." 56

A instrumentalização poderia violar o critério moral do "poder ser si mesmo". Conforme Habermas, "uma pessoa é ela mesma quando age e se justifica perante os críticos. O si mesmo do objetivo em si, que devemos considerar na outra pessoa, manifestase principalmente na autoria de uma conduta de vida, que se orienta segundo exigências próprias". Por isso, se alguém encontra em sua formação como pessoa "a sedimentação de uma intenção alheia", é natural que venha a reagir a ela. Por isso, a aplicação de técnicas genéticas [e a busca dos interesses das futuras gerações em uma deliberação ambiental] "precisa permanecer sensível para levar em consideração as situações e os projetos individuais de vida de todos os indivíduos" 57

A pessoa gerada naturalmente encontra-se na mesma situação que a pessoa programada no tocante à liberdade de levar uma vida conforme seus planos individuais. A vontade dos pais para que o filho tenha aptidão para determinado dom pode acontecer tanto na socialização familiar quanto com um programa genético, pois o filho em questão pode transformar essa expectativa em seus próprios sonhos. Entretanto, uma eugenia liberal não afetaria somente o poder ser si mesmo, simultaneamente produziria uma relação interpessoal assimétrica que questiona a autocompreensão moral de pessoas que agem e julgam de maneira autônoma. Para Habermas: "Ninguém pode depender do outro de modo 
fundamentalmente irreversível." De nada adiantaria outros direitos fundamentais se o ser humano não tiver consciência de si mesmo e se não puder tomar uma posição sobre si mesmo, sobre sua vida. O princípio do discurso de Habermas exige que os afetados pela decisão não sejam excluídos. Eles devem poder dizer não diante de algo que os afete. "É no poder do participante do discurso de dizer "não" que a compreensão espontânea de si mesmo e do mundo, pertencente a indivíduos insubstituíveis, precisa ser verbalizada." 58

Os eugenistas liberais preveem um futuro biopolítico no qual o Estado constitucional democrático ofereceria os meios para compensar a simetria perturbada, instituindo normas que tendam à universalidade. Porém, uma regra de objetivos coletivos, que "ultrapassam a prevenção de males sobre a qual existe uma concordância, intervém anticonstitucionalmente na autonomia privada dos cidadãos". A eugenia de aperfeiçoamento não pode ser legítima em uma sociedade democrática pois não concederia a todo cidadão direito a uma vida autônoma. Eugenistas suprimem o direito da igualdade perante o direito à liberdade para a imposição de suas prerrogativas liberais. A ampliação da personalidade do ser humano ao ponto de ferir o direito à igualdade seria, no mínimo, uma aversão ao consagrado direito fundamental. ${ }^{59}$

Habermas questiona se "eventualmente as gerações futuras vão se conformar com o fato de não mais se conceberem como autores únicos de suas vidas". Alerta que, já nos dias de hoje, com esse "olhar para um futuro possível da natureza humana", precisa-se de uma regulamentação, eis que a "dessensibilização do nosso olhar em relação à natureza humana, que caminharia de mãos dadas com o fato de nos habituarmos a tal prática, prepararia o caminho para uma eugenia liberal" ${ }^{\prime 60}$. O futuro da natureza humana solicita que deixemos o ser humano naturalmente como é, que asseguremos a inviolabilidade à espécie.

É inquietante pensar como as intervenções eugênicas de aperfeiçoamento afetariam o "poder ser si mesmo" e o relacionamento para com os outros, ou seja, compreender-se como único autor da própria vida e ao mesmo tempo tratar as outras pessoas como se tivessem nascido sob as mesmas condições. Hoje a resistência à alteração da identidade da espécie humana pode ser justificada pelo mesmo motivo que as práticas do mundo da vida se adaptam às premissas da moral e dos direitos humanos que fornecem uma favorável existência da dignidade humana acima das diferenças ideológicas.

Em síntese, propõe-se que qualquer decisão que envolva as futuras gerações (tanto em relação à aplicação de técnicas genéticas, como em casos de deliberação ambiental lato sensu) levem em consideração os seguintes princípios bioéticos encontrados no livro de Habermas "O Futuro da Natureza Humana", e acima trabalhados: a) poder ser si mesmo: as deliberações devem permitir que as pessoas mantenham sua identidade; b) não interferir na dignidade humana: as presentes gerações não podem escolher quem é digno de viver ou não; c) não interferir nas escolhas morais do outro; d) autonomia: mínimo de interferência na natureza da pessoa; e) não instrumentalização: as futuras gerações não devem ser tratadas como objetos; f) senso de igualdade: a paridade na deliberação deve significar que os argumentos dos presentes à deliberação tenham tanto valor quanto os argumentos que poderiam ser trazidos pelas futuras gerações, que estão ausentes. 


\section{Conclus Ão}

Este artigo teve como objetivo buscar princípios para o tratamento da matéria ambiental em relação ao seu impacto nas futuras gerações. Para isso, iniciou-se o estudo com a apresentação das teorias da razão comunicativa e da democracia deliberativa de Habermas, extraindo delas parâmetros para a realização de deliberações que envolvam a matéria ambiental, para consolidar a participação igualitária de todos os atingidos pela norma ambiental por meio do agir comunicativo. Percebeu-se que uma democracia deliberativa legítima efetiva-se no momento em que os interesses são postos em um processo de comunicação entre os sujeitos afetados pela norma, ou seja, são válidas as normas às quais todos os possíveis atingidos poderiam dar o seu assentimento.

A democracia concreta deve permitir que os cidadãos atingidos pela norma possam exercer, por meio de sua participação nas deliberações, o "poder ser si mesmo", que é garantido ao passo que haja liberdade em escolher o próprio destino sem a imposição de influências externas. Habermas acredita que a lei deve ser obedecida por sua validade e aceitabilidade racional, ou seja, para que se obtenha resultados racionais é necessário que haja procedimentos discursivos nas negociações ambientais.

Na perspectiva deliberativa, a norma só será válida se respeitar a teoria do agir comunicativo e para isso deve haver a institucionalização das opiniões públicas formalizadas a partir de discursos racionais. Para isso, é necessário um procedimento ideal de deliberação, no qual deve haver a interação entre argumentação pública racional dos membros de uma comunidade para resolver questões coletivas e instituições legitimadas a fornecer os meios para a realização dessa deliberação de forma pública e livre.

Posteriormente, quanto à proteção das futuras gerações, apresentou-se o princípio responsabilidade e o princípio da equidade intergeracional. Segundo o princípio responsabilidade de Hans Jonas, segue-se a ética da responsabilidade se o ser humano deixa ao futuro um meio ambiente em condições iguais de fruição ao que se dispõe na atualidade, ou seja, o dever é não interferir na continuação do meio para as futuras gerações.

Já Habermas, em relação à proteção das futuras gerações, propõe a forma como deve ser regulada a responsabilidade quanto às intervenções humanas, se normativamente reguladas ou sem autodelimitações, de acordo com preferências individuais. Expõe que a primeira alternativa tende a ser a solução, eis que comumente os interesses dos presentes à deliberação ambiental prevalecem sobre os interesses daqueles que ainda não existem. A norma traz limites à deliberação de forma que, ao deliberar, estabelece-se o limite para as decisões ambientais, impedindo que afetem os interesses das futuras gerações.

Mas, apesar dessas previsões normativas, ainda assim é possível reduzir a liberdade de atuação das futuras gerações em cada decisão ambiental tomada. Caso não haja responsabilidade solidária que possibilite aos ausentes o "poder ser si mesmo", as ameaças ao meio ambiente tornam-se hábitos que geram indiferença aos direitos do outro. $\mathrm{O}$ "poder ser si mesmo" garante aos descendentes uma vida sem imposições passadas. Diante isso, se deve limitar, através da segurança estatal, a intervenção humana sobre a natureza (e sobre a vida futura), dado que qualquer erro atual pode castigar irreversivelmente as gerações futuras.

O princípio da equidade intergeracional busca, por meio da solidariedade e da inclusão, a preservação para as presentes e futuras gerações. E, ensina que o ser humano vive reciprocamente com a natureza e nada menos do que recebeu das gerações passadas deve ser 
deixado às próximas gerações. Nesse caso, demonstrou-se indiscutível a responsabilidade que a geração atual possui com a geração subsequente. Além disso, trabalhou-se alguns paradigmas éticos que devem ser observados para conduzir a comunidade a um comprometimento com os que carecem de voz, dado que a natureza humana e não humana deve encontrar no próprio ser humano o seu maior protetor.

Em seguida, demonstrou-se que Habermas, na obra "O Futuro da Natureza Humana”, aborda parâmetros bioéticos para o futuro da humanidade que, embora trate sobre questões relacionadas à aplicação de técnicas genéticas, trabalha, em sua essência, com a ética da espécie humana. Tendo como base os princípios encontrados, uma deliberação ambiental que considere os interesses das futuras gerações deve: a) permitir que elas mantenham sua identidade; b) não interferir na sua dignidade; c) não interferir nas suas escolhas morais; d) garantir sua autonomia, com o mínimo de interferência; e) não tratá-las como objetos; e f) tratá-las com um senso de igualdade.

\section{REFERÊNCIAS}

AYALA, Patryck de Araújo. Devido Processo Ambiental e o Direito Fundamental ao Meio Ambiente. Rio de Janeiro: Lumen Juris, 2011.

BENJAMIN, Antonio Herman Vasconcellos e. Introdução à Lei do Sistema Nacional de Unidades de Conservação. In: . (coord.) Direito ambiental das áreas protegidas: o regime jurídico das unidades

de conservação. Rio de Janeiro: Forense Universitária, 2001, p. 276-316.

BIELEFELDT, Heiner. Filosofia dos Direitos Humanos. Trad. Dankwart Bernsmuller. São Leopoldo: Ed. Unisinos, 2000.

GOMES, Wilson. Esfera Pública política e media: com Habermas, contra Habermas. In: RUBIM, Antônio Albino Canelas; BENTZ, Ione Maria Ghislene; PINTO, Milton José. Produção e Recepção dos Sentidos Midiáticos. 2. ed. Petrópolis, RJ: Vozes, 1998, p. 155-186.

HABERMAS, Jürgen. A Inclusão do Outro: Estudos de Teoria Política. Trad. George Sperber e Paulo Astor Soethe. São Paulo: Ed. Loyola, 2007.

HABERMAS, Jürgen. Comentários à Ética do Discurso. Lisboa: Instituto Piaget, 1999.

HABERMAS, Jürgen. Direito e Democracia: entre facticidade e validade. V. I .Trad. Flávio Beno Siebeneichler. Rio de Janeiro: Tempo brasileiro, 1997.

HABERMAS, Jürgen. O Futuro da Natureza Humana. Trad. Karina Jannini; revisão da tradução Eurides Avance de Souza. São Paulo: Martins Fontes, 2010.

JONAS, Hans. O Princípio Responsabilidade: ensaio de uma ética para a civilização tecnológica. Trad. Marijane Lisboa, Luiz Barros Montez. Rio de Janeiro: Contraponto, Ed. PUC-Rio, 2006.

LEITE, José Rubens Morato; AYALA, Patryck de Araújo. Direito Ambiental na Sociedade de Risco. 2.ed., rev., atual. e ampl. Rio de Janeiro: Forense Universitária, 2004.

LIAN, Henrique. Novo Contrato Social: proposta para esta geração e para as futuras. São Paulo: Planeta Sustentável, Instituto Ethos, 2013.

SARLET, Ingo Wolfgang; FENSTERSEIFER, Tiago. Direito Constitucional Ambiental: estudos sobre a 
constituição, os direitos fundamentais e a proteção do ambiente. São Paulo: Revista dos Tribunais, 2011. SCHIOCCHET, Taysa; LIEDKE, Mônica Souza. O direito e a proteção das gerações futuras na sociedade de risco global. Veredas do Direito, Belo Horizonte, v.9, n. 17. p.109-131, Janeiro/Junho de 2012.

SILVA, José Afonso da. Curso de Direito Constitucional Positivo. São Paulo: Malheiros Editores, 2014.

SOUZA, Leonardo da Rocha de. A Consideração dos ausentes à deliberação ambiental: uma proposta a partir da ética do discurso de Jürgen Habermas. Rio de Janeiro: Lumen Juris, 2013.

SOUZA, Leonardo da Rocha de; TROMBKA, Deivi; ROSSETTO, Daísa Rizzotto. A dignidade da pessoa humana e a problemática questão animal: Um colóquio de natureza ética. Revista Brasileira de Direito Animal, v. 10, p. 83-109, 2015.

SOUZA, Leonardo da Rocha de. Ambivalências da era moderna e a realização dos direitos humanos na sociedade pós-secular, Argumenta, v. 25, p. 221-241, 2016.

SOUZA, Leonardo da Rocha de; RODRIGUES, G. B. As políticas de biossegurança e as futuras gerações. In: Eduardo Sérgio Soares Sousa; Monica Neves Aguiar da Silva, Janaína Reckzzielgel. (Org.). Biodireito I. 1ed. Florianópolis: Conpedi, 2014, v.1.

SOUZA, Leonardo da Rocha de. Direito Ambiental e Democracia Deliberativa. Jundiaí: Paco Editorial, 2013.

\section{Notas de Referências}

(ENDNOTES)

1. Art. 225: Todos têm direito ao meio ambiente ecologicamente equilibrado, bem de uso comum do povo e essencial à sadia qualidade de vida, impondo-se ao Poder Público e à coletividade o dever de defendê-lo e preservá-lo para as presentes e futuras gerações.

2. LEITE, José Rubens Morato; AYALA, Patryck de Araújo. Direito Ambiental na Sociedade de Risco. 2.ed., rev., atual. e ampl. Rio de Janeiro: Forense Universitária, 2004. p. 11.

3. HABERMAS, Jürgen. O Futuro da Natureza Humana. Trad. Karina Jannini; revisão trad. Eurides Avance de Souza. São Paulo: Martins Fontes, 2010. p. 17-18.

4. BENJAMIN, Antonio Herman Vasconcellos e. Introdução à Lei do Sistema Nacional de Unidades de Conservação. In: ___ ( . (coord.) Direito ambiental das áreas protegidas: o regime jurídico das unidades de conservação. Rio de Janeiro: Forense Universitária, 2001, p. 276-316, p. 280-281.

5. Introdução à Lei do Sistema Nacional de Unidades de Conservação, p. 280-281.

6. SOUZA, Leonardo da Rocha de. Direito Ambiental e Democracia Deliberativa. 1. ed. Jundiaí: Paco Editorial, 2013, p. 51.

7. SOUZA, Direito Ambiental e Democracia Deliberativa, p. 58.

8. SOUZA, Direito Ambiental e Democracia Deliberativa, p. 58.

9. HABERMAS, Jürgen. O Futuro da Natureza Humana. São Paulo: Martins Fontes, 2010, p. 3-9. 
10. José Pedro Luchi, Direito e Democracia, p.56.

11. HABERMAS, Jürgen. Direito e Democracia: entre facticidade e validade. Rio de Janeiro: Editora tempo brasileiro, 1997, v. I p.114-115.

12. SOUZA, Leonardo da Rocha de. Direito Ambiental e Democracia Deliberativa, p. 63, com base nos ensinamentos de Jürgen Habermas, Direito e Democracia..., v. II, p.15-21.

13. SOUZA, Leonardo da Rocha de. Direito Ambiental e Democracia Deliberativa, p. 69-70.

14. JONAS, Hans. O Princípio da Responsabilidade: ensaio de uma ética para a civilização tecnológica. Rio de Janeiro: Contraponto, 2016, p. 47-48.

15. HABERMAS, Jürgen. O Futuro da Natureza Humana. p. 18.

16. SOUZA, Leonardo da Rocha de. A Consideração dos Ausentes à Deliberação Ambiental: Uma proposta a partir da Ética do Discurso de Jürgen Habermas, p. 142.

17. SOUZA, Leonardo da Rocha de. A Consideração dos Ausentes à Deliberação Ambiental: Uma proposta a partir da Ética do Discurso de Jürgen Habermas, p. 143.

18. Sobre uma reflexão a respeito da dignidade humana e a questão animal, cf. SOUZA, Leonardo da Rocha de; TROMBKA, Deivi; ROSSETTO, Daísa Rizzotto. A dignidade da pessoa humana e a problemática questão animal: Um colóquio de natureza ética. Revista Brasileira de Direito Animal, v. 10, p. 83-109, 2015.

19. SCHIOCCHET, Taysa; LIEDKE, Mônica Souza. O direito e a proteção das gerações futuras na sociedade de risco global. Veredas do Direito, Belo Horizonte, 2012, v.9, n. 17, p. 111.

20. SCHIOCCHET, Taysa; LIEDKE, Mônica Souza. O direito e a proteção das gerações futuras na sociedade de risco global, p. 121.

21. SARLET, Ingo Wolfgang; FENSTERSEIFER, Tiago. Direito Constitucional Ambiental: estudos sobre a constituição, os direitos fundamentais e a proteção do ambiente. São Paulo: Editora Revista dos Tribunais, 2011, p. 36.

22. HABERMAS, Jürgen. A Inclusão do Outro, Estudos de Teoria Política. São Paulo: Edições Loyola, 2002, p. 242.

23. LIAN, Henrique. Novo Contrato Social: proposta para esta geração e para as futuras. São Paulo: Planeta Sustentável, Instituto Ethos, 2013, p. 79. Nesta obra o autor propõe uma nova leitura do "Contrato Social" de Rousseau.

24. PARDO, José Esteve. O Desconcerto do Leviatã: política e direito perante as incertezas da ciência. São Paulo: Instituto O direito por um planeta verde, 2015, p. 71.

25. PARDO, José Esteve. O Desconcerto do Leviatã..., p. 72.

26. PARDO, José Esteve. O Desconcerto do Leviatã..., p. 71-72.

27. PARDO, José Esteve. O Desconcerto do Leviatã..., p. 71-72.

28. AYALA, Patryck de Araújo. Devido Processo Ambiental e o Direito Fundamental ao Meio Ambiente. Rio de Janeiro: Editora Lumen Juris, 2011, p. 35.

29. AYALA, Patryck de Araújo. Devido Processo Ambiental..., p. 35, com base nos ensinamentos de José 
Joaquim Gomes Canotilho, “Direito Constitucional Ambiental Português”, 2007, p. 2.

30. Ibidem.

31. HABERMAS, Jürgen. O Futuro da Natureza Humana, p. 3-9.

32. HABERMAS, Jürgen. O Futuro da Natureza Humana, p. 10.

33. HABERMAS, Jürgen. O Futuro da Natureza Humana, p. 17-18.

34. HABERMAS, Jürgen. O Futuro da Natureza Humana, p. 21.

35. HABERMAS, Jürgen. O Futuro da Natureza Humana, p. 24-26.

36. Na perspectiva de Habermas, esfera pública é o local em que os interesses, as vontades e as pretensões que afetam a coletividade são exteriorizados de forma aberta e racional por meio de discursos e argumentos (GOMES, Esfera Pública Política..., p. 155). Em outras palavras, a esfera pública é o local onde as pessoas estão juntas coletivamente, argumentando e discutindo (SOUZA, A Consideração..., p. 99)

37. HABERMAS, Jürgen. O Futuro da Natureza Humana, p. 26.

38. HABERMAS, Jürgen. O Futuro da Natureza Humana, p. 26-27.

39. HABERMAS, O Futuro da Natureza Humana, p. 71, 77. Essa manifestação de Habermas é feita pensando nas escolhas que os pais poderiam fazer na genética do filho sem obter deste o consenso e de acordo com as preferências dos genitores.

40. RAU, Johannes. Der Mensch ist jetzt Mitspieler der Evolution geworden. In: FAZ, de 19 de maio de 2001, apud HABERMAS, Jürgen. O Futuro da Natureza Humana, p. 27.

41. HABERMAS, Jürgen. O Futuro da Natureza Humana, p. 28-29,com base nos ensinamentos de R. Kollek, Präimplantationsdiagnostik, Tübingen e Basel (A. Francke), 2000, p.214.

42. HABERMAS, Jürgen. O Futuro da Natureza Humana, p. 30.

43. HABERMAS, Jürgen. O Futuro da Natureza Humana, p.34-35. "A autonomia "é uma das palavras-chave do moderno Iluminismo", pois permite a dignidade humana, proveniente do direito inalienável à liberdade e à igualdade. Para haver autonomia é preciso haver distanciamento da tradição e sua revisão crítica por meio de sujeitos autônomos. A ideia, porém, não é abandonar a própria cultura para adquirir uma tradição comum como base política e jurídica, pois em muitos países "precisam conviver pessoas de diversas tradições religiosas e culturais". Isso geraria uma homogeneização obrigatória (ou limpeza étnica), com a consequente perda de equilíbrio das tradições, que facilmente acabaria em fundamentalismo (BIELEFELDT, 2000, p. 50-51, 57). Por isso, a "equiparação de situações de vida" e as "posições de poder factuais" almejadas não podem ser conquistadas por meio de "intervenções padronizadoras", já que isso resultaria em aplainar as diferenças em busca da igualdade, ao invés de reconhecer as diferenças para garantir autonomia (HABERMAS, 2007, p. 235-236). Portanto, a efetivação dos direitos humanos passa pela garantia de uma autonomia intersubjetivista, que considera "que o livre desenvolvimento da personalidade de cada um depende da realização da liberdade de todos" (HABERMAS, 1999, p. 27)." (SOUZA, Leonardo da Rocha de. Ambivalências da era moderna e a realização dos direitos humanos na sociedade pós-secular, Argumenta, v. 25, 2016, p. 227)

44. HABERMAS, Jürgen. O Futuro da Natureza Humana, p. 35. 
45. HABERMAS, Jürgen. O Futuro da Natureza Humana, p. 37-38; p. 39, nota de rodapé n. 19. Essa segunda questão é tratada por Allen Buchanan em From Chance to Choice, 2000, p. 4, com base na teoria da justiça elaborada por John Rawls.

46. HABERMAS, Jürgen. O Futuro da Natureza Humana, p. 40-41.

47. HABERMAS, Jürgen. O Futuro da Natureza Humana, p. 41.

48. HABERMAS, Jürgen. O Futuro da Natureza Humana, p. 41.

49. HABERMAS, Jürgen. O Futuro da Natureza Humana, p. 42.

50. HABERMAS, Jürgen. O Futuro da Natureza Humana, p. 44-46.

51. HABERMAS, Jürgen. O Futuro da Natureza Humana, p. 57.

52. HABERMAS, Jürgen. O Futuro da Natureza Humana, p. 57-58.

53. HABERMAS, Jürgen. O Futuro da Natureza Humana, p. 59, nota de rodapé n. 34.

54. HABERMAS, Jürgen. O Futuro da Natureza Humana, p. 67-70.

55. HABERMAS, Jürgen. O Futuro da Natureza Humana, p. 68-70.

56. JONAS, Hans. O Princípio Responsabilidade, p. 47-48.

57. HABERMAS, Jürgen. O Futuro da Natureza Humana, p. 77-78, 83.

58. HABERMAS, Jürgen. O Futuro da Natureza Humana, p. 79, 84-88.

59. HABERMAS, Jürgen. O Futuro da Natureza Humana, p. 90, 92. “Aristóteles já dizia que a democracia é o governo onde domina o número, isto é, a maioria, mas também disse que a alma da democracia consiste na liberdade, sendo todos iguais. A igualdade, diz, é o primeiro atributo que os democratas põem como fundamento e fim da democracia. E assim ele acaba concluindo que toda democracia se funda no direito de igualdade, e tanto mais pronunciada será a democracia quanto mais se avança na igualdade." SILVA, José Afonso da. Curso de Direito Constitucional Positivo. São Paulo: Malheiros Editores, 2014, p. 131, com base nos ensinamentos de Aristóteles na obra Política.

60. HABERMAS, Jürgen. O Futuro da Natureza Humana, p. 93, 98. 